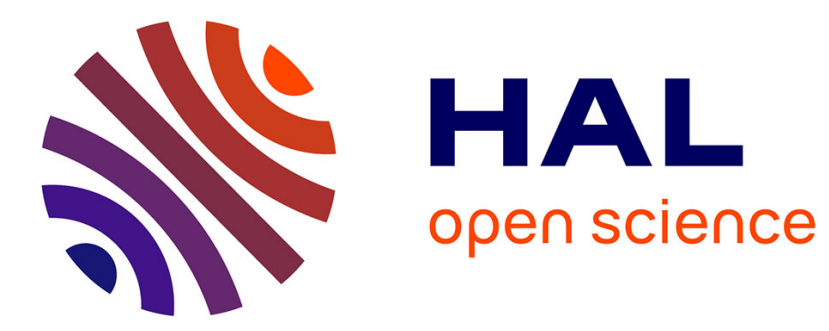

\title{
Does prosody play a specific role in conversational humor?
}

\author{
Roxane Bertrand, Béatrice Priego-Valverde
}

\section{To cite this version:}

Roxane Bertrand, Béatrice Priego-Valverde. Does prosody play a specific role in conversational humor?. Pragmatics and Cognition, 2011, 19 (2), p. 333-356. hal-01306812

\section{HAL Id: hal-01306812 \\ https://hal.science/hal-01306812}

Submitted on 25 Apr 2016

HAL is a multi-disciplinary open access archive for the deposit and dissemination of scientific research documents, whether they are published or not. The documents may come from teaching and research institutions in France or abroad, or from public or private research centers.
L'archive ouverte pluridisciplinaire HAL, est destinée au dépôt et à la diffusion de documents scientifiques de niveau recherche, publiés ou non, émanant des établissements d'enseignement et de recherche français ou étrangers, des laboratoires publics ou privés. 


\title{
Does prosody play a specific role in conversational humor? Roxane Bertrand \& Béatrice Priego-Valverde Roxane.Bertrand@Ipl-aix.fr; Bea.Priego-Valverde@Ipl-aix.fr
}

\begin{abstract}
In this paper we use Conversation Analysis (CA) to investigate conversational humor in talkin-interaction. We attempt to better understand how the latter is produced and co-constructed by participants in accounting for the devices used by participants in their sequential environment. The framework of CA enables us to take into account the various means available to speakers to communicate, orient to the others, etc. From our data, reported speech, confirmation request/answer and repetitions appear as the main discursive devices to create humor (presented as the result of the appearance of the incongruity). We focused on prosodic cues that are strongly involved in these devices and then contribute to the humorous tonality of the talk. Finally, the co-construction of conversational humor is mainly described through the notion of orientation and prosodic orientation.
\end{abstract}

\section{CONVERSATIONAL HUMOR}

Conversational humor is the main focus of this article. Following Attardo (1994) or PriegoValverde (2003) among others, we know that it is a very complex phenomenon and that its boundaries are very difficult to delimitate principally because it is a multiform phenomenon. It can be short and correspond to a single utterance or it can be very long like the canned jokes or a whole sequence co-constructed by the participants. Its "tonality" is also very difficult to determine. Conversational humor may be simple jokes, teasing, wit, sarcasm, word play and so on. And most of the time, it may be several things at the same time (teasing jokes, friendly wit etc). Thus we can say that humor is often both friendly and aggressive. Because of this ambivalence, the interlocutors have to be very close to be able to perceive and/or appreciate humor. But humor, even between close friends, have its own boundaries or more precisely, humor has the boundaries fixed by the participants themselves which correspond to social, moral and of course personal limits. Thus, the subjects have to be on the same wavelength to make humor work. In our data, thanks to their close relationship, the two speakers are on the same wavelength and they laugh about the same things. Thus, each speaker chimes in on the other's purpose until creating a whole humorous sequence.

One thing is sure: conversational humor is a very interactive phenomenon. Usually, it appears as a lightning thanks to a thing done or said by the interlocutor and on which the humorist speaker chimes in or continues until it is turned into derision. Conversational humor is thus directly linked to the context. And in a conversational setting, the context has to be understood in a broad sense: the situation hic et nunc, the participants' conversational history, their relationship and their shared knowledge.

Using the framework of Conversational Analysis (henceforth CA) (Couper-Kuhlen \& Selting 1996; Couper-Kuhlen \& Ford 2004) we attempt to better understand what is precisely 
conversational humor and how participants co-construct it. Among the available resources, participants can use prosodic cues. Prosodic means are intended here as the whole phenomenon related to pitch level, pitch register, syllable duration, accentuation, tempo, but also the 'phonetic details' (Local 2007) as vocal quality for instance which are relevant to account for turn-taking in talk-in-interaction (Ogden 2004). Following Local for which prosodic cues must be analyzed in situ, we claim that conversational humor combines several criteria which make it difficult to describe it without taking into account the context and the combination of prosodic cues with the others resources (like the lexicon for instance). According to us, the last point explains why it is not surprisingly that there is no ironical tone of voice (Bryant \& Fox-Tree 2005). Indeed, our conception implies that there is no biunivocal form-function relation between a linguistic device and a prosodic form (Hirschberg 2002; Di Cristo et al. 2004). We shall see in this paper that if prosodic cues do exist in our humorous sequences and can play a crucial role, they are not humorous per se but one part among others of a congruence of elements that make humor appear (Attardo et al. 2003).

\section{CORPUS CID}

\subsection{General presentation}

The CID, audio-video taped recorded data elaborated in the $\mathrm{LPL}^{1}$ (Bertrand 2008) is a unique resource for the analysis of speech in interaction. It is constituted by 8 hours audio-video recorded dialogues. The interactions are transcribed and annotated to be useful for different fields: phonetics, prosody, syntax, discourse and non-verbal analysis (see the ToMA project (OTIM in French, Blache et al 2009). This goal required a particular protocol of experiment, which allowed us to obtain dialogues interesting both for the interactional level and the phonetic and prosodic approach.

\subsection{Device and protocol}

At this point, the CID is composed by 8 one hour interactions in French ${ }^{2}$. The dialogues between two interlocutors are based on instructions given by the experimenters before the recording. 2 series of recordings were done with two different instructions: (i) according to the first one, the subjects had to speak about professional conflicts (ii) in the second one, they had to talk about unusual situations they had experienced. These two instructions were presented by the experimenters as a topic support allowing the subjects to begin quickly the interaction but they were only a support because the experimenters said right away to the subjects that they could digress from these topics if they wanted it.

\subsection{The participants and their conditions of recording}

10 females and 6 males are implicated in non mixed and face to face interactions. The 16 participants are French native and half of them come from Southern France. At the moment of the recording, all were living in Southern France for at least several months and knew very well the place where the recordings took place. This last aspect was a necessary condition to minimize the stress such a condition of recording (video taped) entails. All the participants were thus selected among the members of the laboratory but nobody knew the reason why they were recorded. Otherwise, all were chosen according to their high level of acquaintance. This condition guaranteed the fact they shared a "conversational history" (Golopentja 1988). Such a sharing favored more spontaneous and fruitful exchanges and a certain ability to digress from the instructions of the beginning.

\footnotetext{
${ }^{1}$ This corpus, named Corpus d'Interactions Dialogales (Corpus of Interactional Data) was collected by the authors of this paper at the LPL (Laboratoire Parole et Langage).

${ }^{2}$ The final goal is to obtain 20 dialogs.
} 
Each time, the two speakers were recorded in an anechoic room. They had a headphone in order to record them on separate tracks. They were also video recorded.

\subsection{Conversational characteristics of the data}

If all the subjects tried to respond to the instructions, they frequently digressed by speaking more freely, creating thus some conversational sequences. The CID is an intermediate corpus between authentic and natural data and orientated task data (Anderson et al. 1991).

Otherwise, all the dialogs presented in the CID are very close to conversational interactions. Among the different characteristics, only the external goal due to the instructions distinguishes them from real conversations that have an inward goal, centred on contact (Vion 1992).

Except this criterion, as in real casual conversations, we notice:

-a total symmetry between the participants in terms of status and positions. Theoretically, all of them have the same rights and the same duties, especially those to be alternately speaker and hearer (Sacks et al. 1974):

-an apparent informality that carries on as much in the discourse (the two participants can speak about all and nothing, in a spontaneous way, without a precise goal) as in the interaction itself. Indeed, as Schegloff and Sacks (1973) showed, in a conversation, no explicit rules exist concerning the order of speech turns, their duration, all of that being determined progressively;

-the absence of a tierce person to distribute the speech turn, like in a debate for instance.

Finally, if the dialogs of the CID are globally conversational, they reflect also a heterogeneity of the various discursive sequences present in every interaction. So, here also, we can notice numerous narrations (due to the instructions), but also some descriptive, argumentative or explaining sequences.

\section{TYPE OF HUMOR IN THE CID}

In this preliminary study, we will analyze 1-hour dialogue with the first instruction. The choice of this dialogue is based on the relationship between $\mathrm{A}$ and $\mathrm{L}$ who exhibit a close acquaintance between them. This dialogue seemed to be the closer to real conversations previously analyzed in Priego-Valverde (2003). Thus we can say that, even if this corpus was constituted in a laboratory and with an instruction, we observed the same kind of humor as in authentic conversations ${ }^{3}$. The only difference is the fact that here, humor usually appears in narrative sequences.

The humorous schema observed here is most of the time the same, classic schema: (i) presence of a "connector" (Greimas 1966) that carries two possible and different scripts (Raskin 1985). The first is logical and expected and the second is illogical, sometimes absurd, unrealistic and of course unexpected; (ii) the "disjunctor" (Morin 1966) actualizes the second script and the gap between what is expected and what really happens creates the humorous effect. This gap is the origin of what we usually call the "incongruity" (Bariaud 1983). One of the issues in this paper will be to show whether and how the prosodic level contributes to mark this gap between what is expected and what is really produced.

This gap may be created by several devices and we shall see here two of them. The first one is reported speech that more or less explicitly actualizes two different voices speaking through the speaker, even if the reported voice may be fictitious. The second one implies confirmation answer/request through lexical repetitions allowing speaker to create, step by step, a distance between himself and his own discourse. In this way, humor appears here as a case of "double

\footnotetext{
${ }^{3}$ Because of the instruction of the beginning, we have a lot of narrative jokes in this corpus:
} 
voicing" (in Bakhtin's sense) during which the speaker actualizes a second voice telling unrealistic and humorous purposes. We shall see that according to the discursive device, the connector and the disjunctor can be merged (in the same words or expressions for reported speech) or can be separate (after a space of some words or turns for repetitions).

Both kinds of humor have in common that they are accepted by the interlocutor who laughs and who enters with the speaker in a humorous mode of communication until creating a "joint fantasy" (Kotthoff 2006) where each participant chimes in on the other's purpose. We described this through the notion of interactional orientation that refers in CA to the fact that "throughout the course of a conversation (...) speakers display in their sequentially "next" turns an understanding of what the "prior" turn was about' (Hutchby \& Wooffitt 1998: 15).

In the next section, we will show how speakers create humorous sequences in adapting the classic schema mentioned above (connector/disjonctor) according to whether the speaker uses reported speech or confirming turns. We will observe how vocal cues make humor hearable to the interlocutor in contributing to mark the gap between what is expected and what appears in these specific devices but also how vocal cues enable the interlocutor to orient to the main speaker's discourse.

\section{ANALYSIS}

\subsection{The humorous reported speech}

When speakers report the speech or thought of another person through reported speech the main question addressed is who is speaking and for what reason. According to the type of function assumed by reported speech, the main speaker may or may not be precise about the origin of the words. Reported speech is not only used to report words but also to enable speakers to convey their assessment of the utterance while reproducing it (Holt 2000), or to effect other functions such as increasing one's standing or saying something without really assuming it (given the duality of the other voice) (Bertrand 2003: 3). We will analyze here its use in interaction (as Holt, 2000) which is the best way to show functions other than a simple reproduction. Reported speech indeed is a very relevant discursive device that benefits from a diversity of means. Among others, vocal means can be used to make explicit the other voice (e.g., Couper-Kuhlen 1999; Klewitz \& Couper-Kuhlen 1999; Bertrand \& Espesser 2002).

Because of the design and the instruction of the CID, it was not surprising to find numerous sequences of reported speech used, for example, to describe situations in which participants were involved or to illustrate a relationship between the different protagonists in the unusual situations described in the CID storytelling framework. But cases of reported speech used to create humor apart from the cases described and directly linked to the stories were unusual. However, we found several instances of this phenomenon.

In our examples, only recipients make use of reported speech to create a humorous utterance. The following example (1) is the only one where the main speaker A of the narrative sequence produces the humorous utterance in order to ease the nature of his own previous talk. This reported speech appears in a typical sequence called «aside » (Selting 2000) which corresponds to a parenthetical sequence in a narrative sequence.

- Tu es un vilain / You're a bad boy ${ }^{4}$

\footnotetext{
${ }^{4}$ The translation of the examples is at the end of this paper.
} 


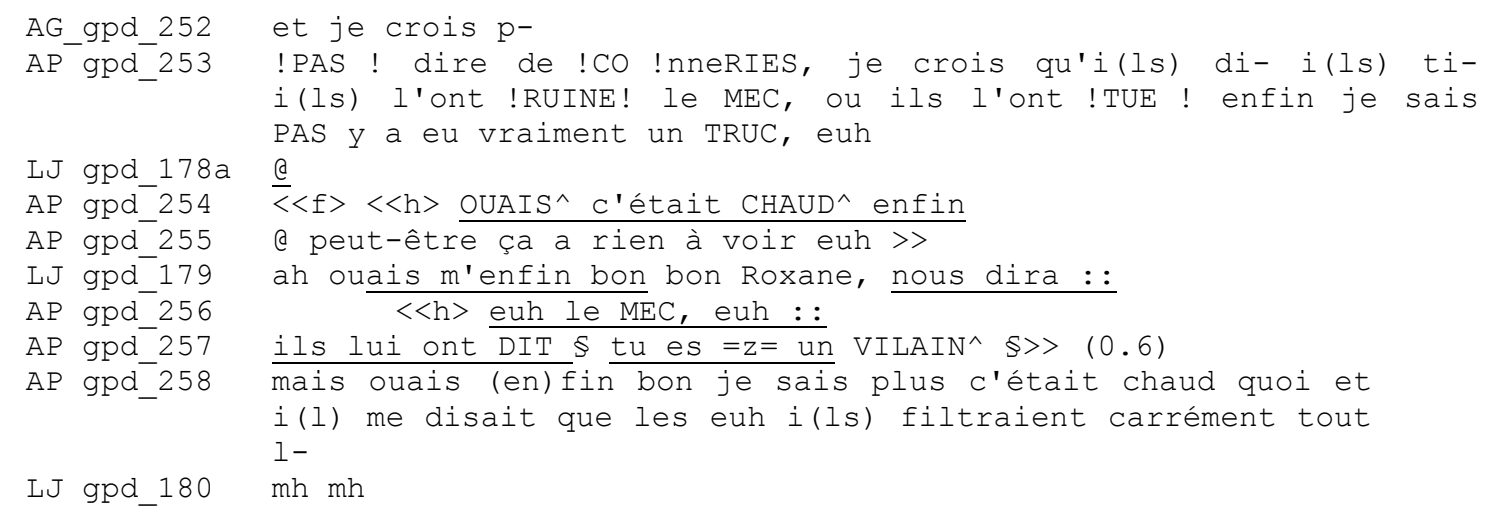

The two subjects are speaking about the way pornography is perceived in Saudi Arabia, a country were L lived few years ago. Digressing around this topic, they evoke the case of a man who, apparently, had big problems with the justice because he would have seduced a woman via internet. The reality of the situation they evoke seems relatively serious and dramatic. But the nature of his discourse (too dramatic) and the vocal cues of the utterance in 257 strongly contrast with the previous story told by A. In this previous discourse, we can distinguish a first phase in which A tells the story using emotional words with emphatic accents. When $\mathrm{L}$ reacts to this phase in an unexpected mode (in laughing and in expressing his doubt (178-179), AP expresses (255, in overlapping) a mitigation in a typical delivery (increasing loudness associated to laugh in the voice). This mitigation is followed by a reported speech that also functions as mitigation (257) and eases this previous story. The 'voice' is assignable to an abstract figure: the voice of the 'Saudi justice'. The reported speech used refers to an invented reported speech (as defined by Vincent \& Dubois 1997). For authors, reported speech is not limited to a strict definition (report word) but also concerns utterances that have never been expressed. Such a reported speech is usually neither anchored in the past nor the present time. Conversely here the reported utterance is strongly anchored in the reporting situation. Moreover, even if AP uses the design of reported speech (prefatory, introductory verb) both the incongruity of his utterance and of his source clearly ensure that words exhibited as repeating words could not have been delivered

The humorous aspect of the utterance gpd 257 is due to the use of the terms "bad boy"/"vilain" - an infantile and derisory term that is animated through Saudi Arabian law expressed with a teacher voice - (overarticulation, lower pitch register, and an intonation risefall contour on 'vilain ${ }^{\wedge}$ '). This utterance contrasts with the last one. All these parameters (invented reported speech anchored in the past, infantile term in the Saudi law voice and vocal cues) contribute to reinforce the gap between what is expected and what really happens and constitute the incongruity of the utterance. Otherwise we notice that the connector and the disjonctor seem to be merged. Indeed, the terms "bad boy"/"vilain" seem to function both as the connector and the disjonctor. If the term carries out a punishing script (by the Arab law in the expected script), it also infers an infantile script and it refers more to the moment the children are on recess and when they told off by the teacher.

This turn is followed by a long pause. After this pause the speaker comes back to his previous story with his own voice and AP concludes repeating "it was hot"/“c'était chaud". As at the beginning, the two expressions function as boundaries of the aside sequence. Moreover, this sequence provides an example of metapragmatic function of humor that is used by the speaker to save his own face (Priego-Valverde 2003).

In the following example (2), we observe the similar situation with only the change of the animator (i.e the interlocutor). 


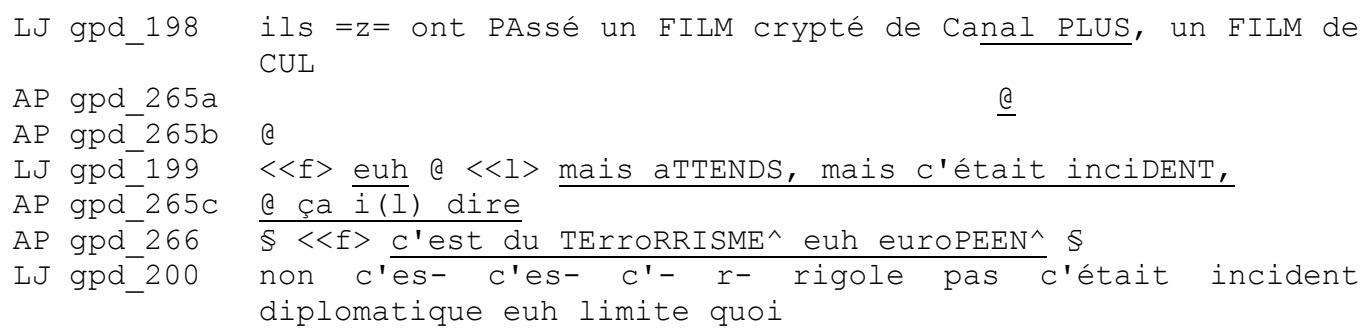

In this excerpt, LJ goes on telling about the years he spent in Saudi Arabia. He evokes a French TV channel that broadcasts French programs or programs in French language outside of France. During his narration, he explains that, one time, the channel made a mistake and broadcasted a pornographic movie.

Despite AP's laughs, LJ tries to explain him how serious this mistake was and how this mistake was quite a diplomatic incident (199, 200: "don't laugh"/"rigole pas").

Despite the serious tone and his laughter, LJ wants to go on explaining his story. AP laughs and produces (266) an utterance expressed in a typical vocal quality (extreme harschness) associated with high pitch register and increased loudness. Contrary to (1), there is no the explicit design of a reported speech but prosodic cues mark this utterance as belonging to another voice. Once again, the reported speech is not assignable to a real character and may correspond to the Arabian authorities. The humorous aspect of the utterance becomes an exaggeration as "European terrorism" is used to qualify a simple movie.

Simultaneously, the overlapping (199-266) contributes to show the clash between two modes of communication: LJ's wants to stay in a bona fide communication (Raskin 1985) and AP wants to switch into a humorous mode. The speaker's comment ("don't laugh"/"ne rigole pas") provides evidence that LJ understands the humorous tonality but he does not want to switch into it even if he laughs.

The two following examples ( 3 and 4) illustrate instances of humor designed to comment on a protagonist in the narrative. The recipient's design in this utterance shows his orientation to the speaker's storytelling. The main speaker produced sufficient information enabling the listener to chime in on the caricature of one of the story's protagonist. We observe that both participants converge in producing simultaneously reported speech, the first in an illustrative function and the second in a humoristic function. Contrary to the previous example, the overlapping reported speech contributes here to enhance the strong convergence between the two participants to create a joint fantasy.

\section{- Végétarien / vegetarian}

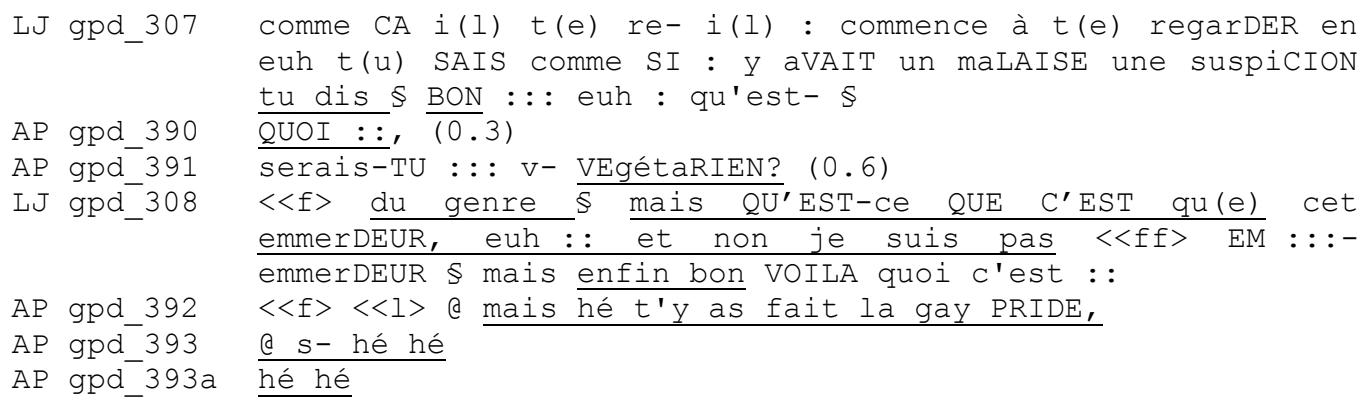


In this excerpt, AP talks about his first meeting with his cousin's boyfriend. The meeting was not a good memory because the boyfriend was a very shy man and did not speak at all, which is not a good way to begin a relationship with someone. This narration evokes to LJ some memories about a man he met when he was doing some archaeological dig. Therefore, LJ explains that he met a man he considered strange because he did not drink coffee or alcohol nor eat meat.

In this context, the two participants produce simultaneously an instance of reported speech: the reported speech of AP (390) completes the last utterance of LJ, and in fact is partially stated in overlap. The delivery of AP is very specific: the first part of its turn is accented and lengthened but in a low register and loudness. Then AP pauses and in this pause LJ hesitates as if waiting for the following utterance. AP then produces the second part of the turn in a specific form: the inversion of the subject (very rare in French spoken language), the conditional associated to the prosodic delivery (lengthening of the subject 'you' and the high rise contour on the last syllable of "vegetarian") and the absurdity of the question create humor. LJ simultaneously produces a reported speech dialogue (not designed to make anyone laugh) in which he contrasts 2 figures (the other man animated by AP and himself) with a different prosodic device. The following utterance in 392 also overlapping laughing with high register and loudness. Both utterances (308 and 392) exhibit a crescendo in the high register and loudness.

This congruence of activities (simultaneous reported speech, overlap) illustrates the strong cooperation and the alignment between participants that is one of the criteria of conversational humor. Its success depends on the participants' shared knowledge/representations of the prototypical figure mentioned here (491). The shift in vocal cues comments on representations one can have about vegetarians (weird people) but is also a comment on AP's part on the figure he animates in this utterance. Otherwise, the reported speech is typically a display of orientation to LJ's discourse: it comments on the discourse by chiming in on it.

- Noir bizarre / black weird

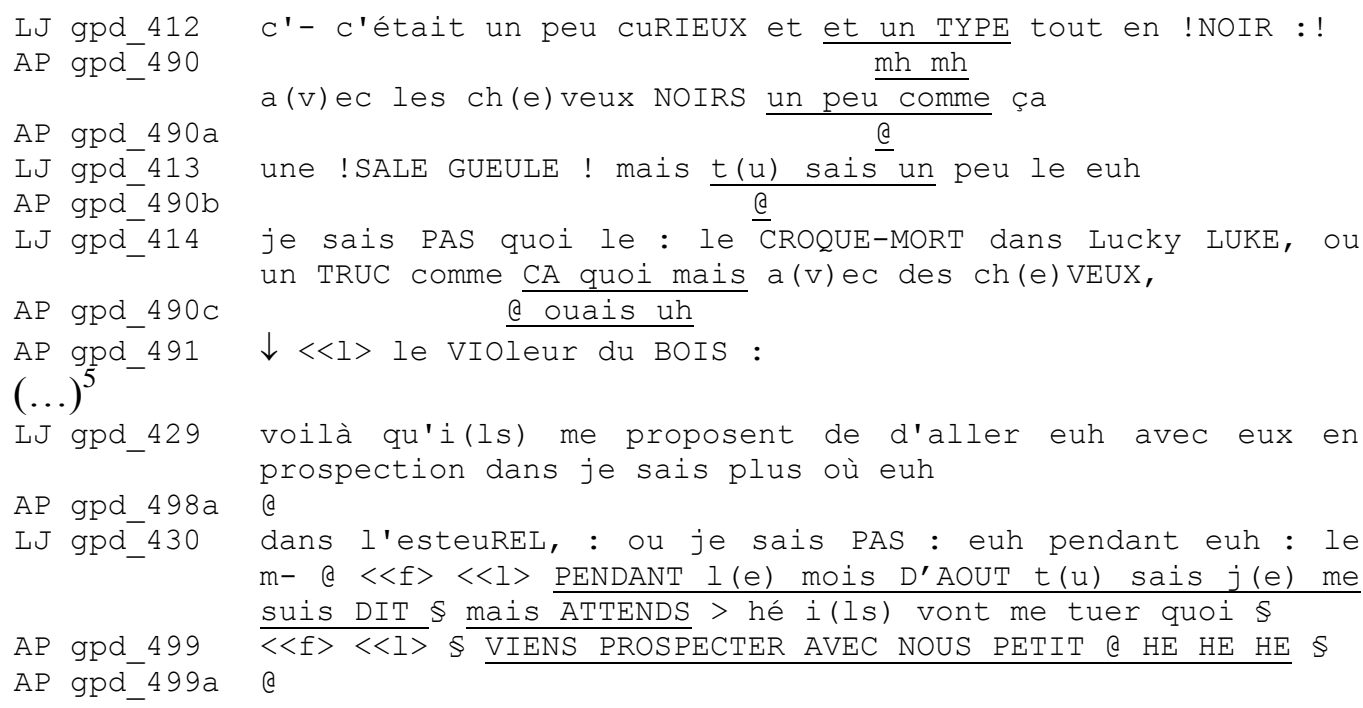

Here, LJ tells how he met with a very strange and scary man during his archaeological prospection. It is by focusing on this scary aspect that the two interlocutors will develop a humorous sequence exaggerating the man's scary aspect: "the rapist of the wood"/"le violeur des bois"; "black weird"/“"noir bizarre".

\footnotetext{
${ }^{5}(\ldots)$ refers to a truncation of the example into two excerpts.
} 
In 490 AP already grunted (with its laugh and "mh") announcing his following turn in 491 in a low pitch register and in descending line. We also heard a hoarse voice in this utterance that will increase in the next utterance (499) which is the vocal animation of the figure presented in 491.

We observe a clear mapping between enunciative and prosodic devices: both interlocutors make use of reported speech and express the same voice in the overlap phase. We notice a higher pitch register and loudness, a typical vocal quality (hoarse voice) which corresponds to the representations shared by the interlocutors to refer to the character in question in the narrative. The vocal cues enable the participants to typify a character that is shared by a community (Klewitz \& Couper-Kuhlen 1999) more specifically here by both interlocutors.

More globally in the last examples, humor is inferable from the prosodic cues that refer more or less explicitly to another voice. But it is not the vocal cues per se but the vocal cues which enable us to say that this utterance is a case of double-voicing that is destined to provoke laughter.

\section{- Le chocolat chaud / the hot chocolate}

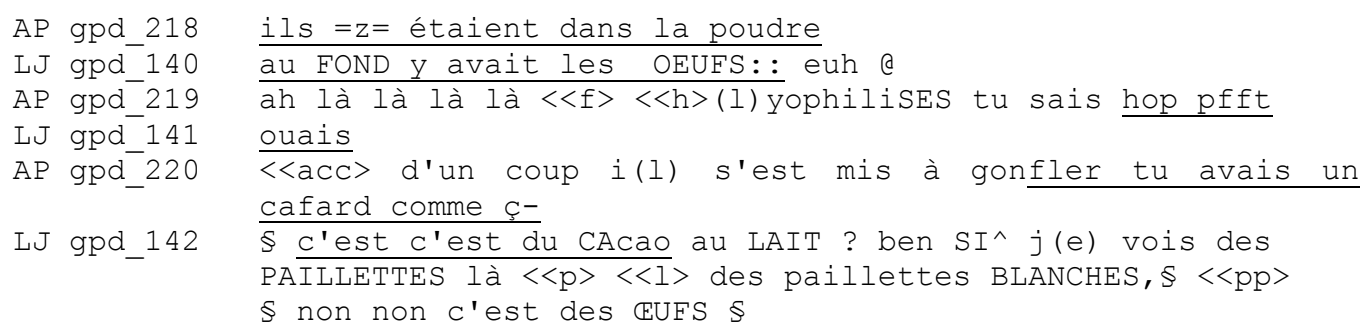

In this excerpt, LJ evokes the time when he went with a friend to a coffee shop to drink a cup of hot chocolate, in which he found a cockroach.

Here, the fictive reported speech (142) seems to be an internal reflexion that LJ shares with the interlocutor. It is self-disparaging kind of humor (Priego-Valverde, 2007) which allows to mock himself and the situation. He produces two voices (himself and probably, the friend of AP): the two first parts of LJ's turn refers to his own voice in the reported speech. They are a confirmation request without answer but an assertion that follows in the sense of the previous question. Prosodically they are both expressed in the same pitch register, and with a rising contour of question for the first part and a rise-fall contour for the second (with the higher pitch peak on "si" / "if", 142). This prosodic device contrasts with the final part of LJ's turn that exhibits a flat melodic configuration and in a pianissimo voice. The two voices are prosodically contrastive. We confirm that when more than one figure is reported, separate prosodic marking may coincide with the different voices (Klewittz \& Couper-Kuhlen 1999: 466).

This example clearly illustrates yet another case of strong agreement between participants. In reporting here a narrative sequence in which he has never been but as if he were a protagonist of the story (instead of AP), LJ displays an orientation to the prior discourse of AP: not only protagonist but also the reported situation itself is fictitious.

\subsection{Summary}

In this previous sub-section, we showed the relevance for participants in talk-in-interaction to use the design of reported speech and/or to make hearable another voice in their discourse in order to create humoristic sequences. We showed that multiple reported speech could appear simultaneously in both the discourse of the main speaker and the recipient, with an illustrative function for the former and a humorous function for the latter. The using of the same devices at the same time for both participants reveals a strong agreement between them. It can be 
interpreted in the general framework of the interactional orientation (Hutchby \& Wooffitt 1998). With his reported speech, the recipient chimes in on the previous talk exhibiting then his strong orientation to it. We also showed that the reported speech analyzed here is invented and precisely anchored in the reporting situation and in the time, conversely to what Vincent \& Dubois (1997: 60) have described under this term. This point contributes to the incongruity of the humorous utterance ("repeated" words have never been delivered). In the same way, the second important point is the abstract or fictitious figure in the reported speech that is animated with unexpected words associated to a typical delivery. Vocal cues are indeed strongly involved in the sequences through different shifts that do not serve to delimit boundaries but rather play a deictic role (Couper-Kuhlen 1999). We confirmed that vocal cues are crucial to make the other voice hearable and understandable. They enable the speaker to typify a character on which members of the same community share knowledge and typical representations (Klewitz \& Couper-Kuhlen 1999). All these parameters contribute to the creation of conversational humor by reinforcing the gap between what is expected and what really happens.

\subsection{Repetitions and confirmation requests/answers}

In the following sub-section, we observe a few examples of humor that appear in a sequential environment involving repetition sequences and confirmation request and answer. These phenomena are crucially interactional in explicitly showing the co-construction of the discourse by participants (Perrin et al. 2003). Moreover, we show that prosodic cues are involved in these devices and strongly contribute to the interactional orientation (defined above) and more specifically to the prosodic orientation (Szczepek-Reed 2006). Finally, we show that the connector and the disjonctor here are produced separately by using different types of shift in prosodic cues.

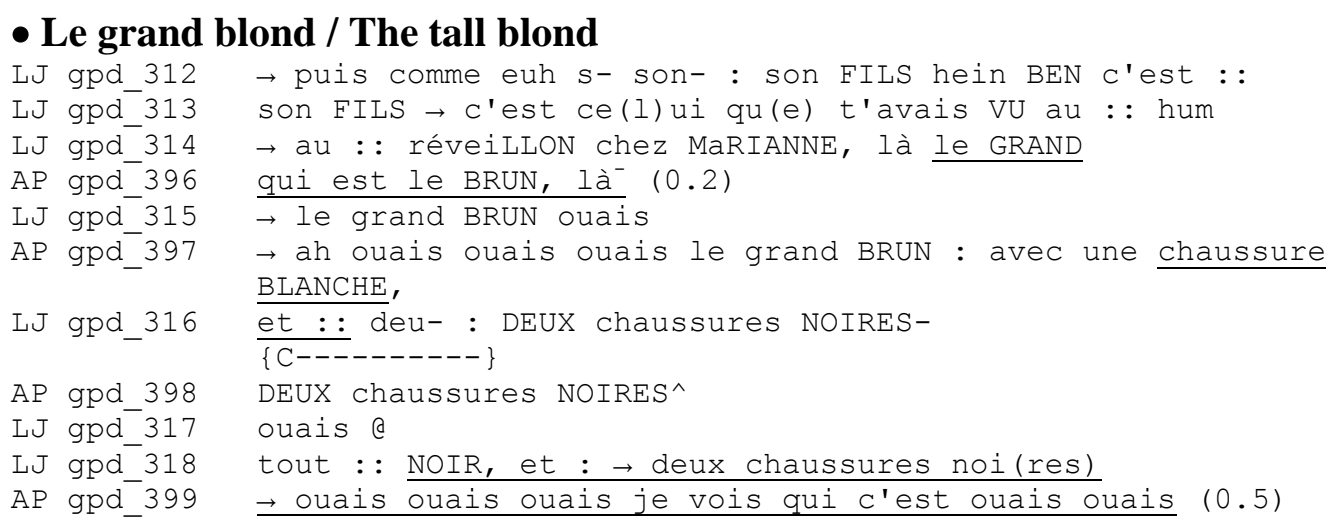

The two interlocutors are speaking about a third person that LJ met when he was at an archaeological dig. LJ describes him as a tall and brown man. AP proceeds to produce humor ("The tall brown with a white shoe"/"Le grand brun avec une chaussure blanche"). The humorous aspect of this sentence is based on an "intertextual" reference (Kristeva 1969) to a very famous French movie called "The tall blond with a black shoe".

From 312 to 314 , LJ expresses his story in a narrow span and flat configuration. The second part of the "connector" initiated in 314 is the subject of a confirmation request expressed by AP (in 396) with a rise on "BRUN / Brown" followed by "là / here" with a high plateau. LJ produces his confirming answer in a flat configuration. Then AP produces the disjonctor that consists of two parts. The first one (397) is a backchannel that confirms and supports the previous confirmation answer. The second one ("chaussures blanches"/“white shoes") refers to the intertextual reference. It is interesting to note that each part corresponds to an intonative unit. The first is produced in the same configuration of the previous utterance of the main 
speaker (flat configuration, level pitch), while the second is ends in a rise movement for which it is difficult to decide if it is a final or a continuation rise. After the overlap LJ alludes to AP's story by repeating his utterance (316) with an accentual arch (Di Cristo 2000) which prosodically merge the three words in a single unit and makes it emphasised ("DEUX chaussures NOIRES"/“TWO BLACK shoes"). Finally, AP ends (398) this parallel sequence by orienting to the story of $\mathrm{LJ}$ and repeating the same utterance with a prosodic mapping (Szcezpeck-Reed 2006) through the accentual arch. Finally in 398, his discourse functions as a backchannel repetition (called complex backchannel, Laforest 1992) with an assessment of the content but more specifically an assessment - or at least a real take into account - of the tonality (humor) which ends in a rise-fall pitch contour. The laughter in his voice also supports this point. The final sequence exhibits another repetition with a prosodic mapping (flat configuration) ("deux chaussures noires"/"two black shoes") and AP finally ratifies and concludes this sequence (in 399) also with a flat configuration on the whole followed by a long pause $(0.5 \mathrm{~s})$.

This sequence highlights the co-construction of a parallel sequence involving humorous tonality. The linguistic devices are confirmation request, answer and repetition with lexical and prosodic mapping.

In the following example, contrary to the previous example in which we showed an orientation through the use of lexical repetitions, we show an instance of prosodic orientation only through a copy of the prosodic cues. This excerpt appears in the same narrative sequence as the example 6.

\section{- I'IRA}

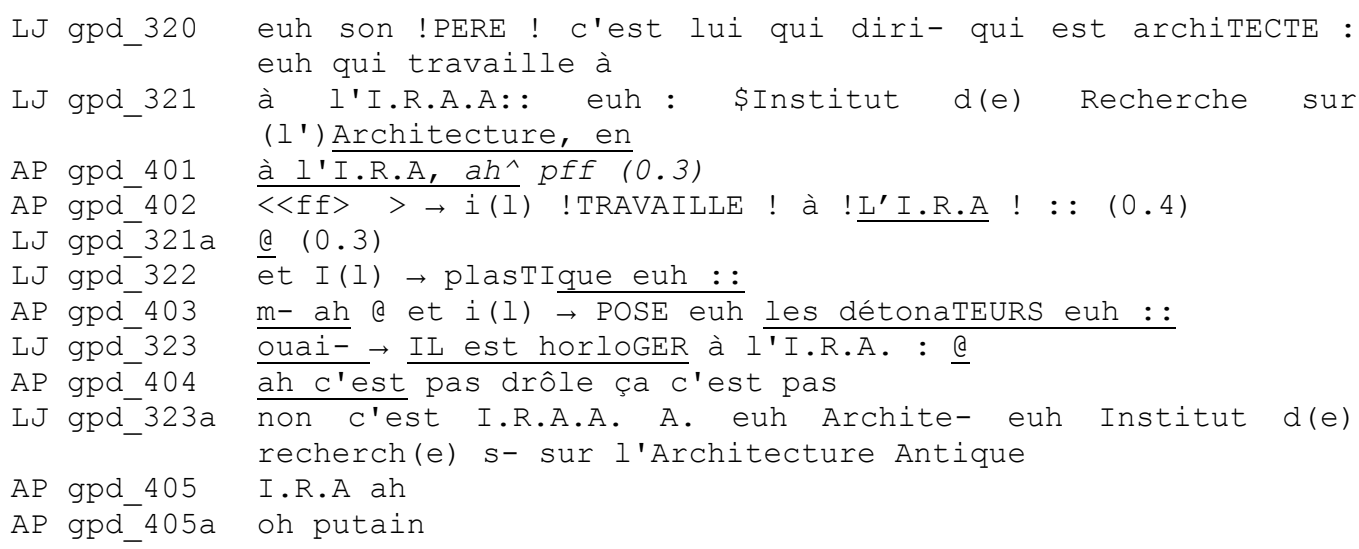

In this sequence, the two participants are speaking about the archaeological dig LJ did some years ago. This excerpt is a part of a long narrative sequence about this topic in which he tells several anecdotes. He evokes one person who is working to the I.R.A.A. i.e. the Research Institute of Antique Archaeology. LJ pronounces the two A's (the corpus shows it) but of course, AP elaborates on this acronym which is phonetically very close to I.R.A., the Irish terrorist organization. In other words, by elaborating on this acronym, AP makes it the polysemic connector that allows him to switch from a bona fide communication about the archaeological searching into a non bona fide communication about terrorism. The acronym I.R.A. becomes thus the disjonctor actualising the second script, a humorous and fictitious script about terrorism.

The switch from a serious to a humorous mode of communication is totally accepted by LJ who does not seem to be disturbed by the interruption of his narration. On the contrary, he shows his complete adherence to the humorous mode of communication beginning by 
laughing and then producing an utterance about terrorism ("he blows up"/"il plastique"). From 321 to 323 , we have a short joint fantasy where each speaker overbids on the other's sentence.

The end of this short sequence is due to the instigator himself (AP: "that's not funny"/"c'est pas drôle"). To end this sequence, he produces a metacommunicative utterance evaluating as not funny (despite the laugh) what was just said. Once again, LJ follows his interlocutor and goes back to a serious mode of communication to give the real signification of the acronym. His narration can proceed hereafter (324).

The disjonctor (the first time where IRA appears in the discourse of A) belongs to a turn composed of two parts (an adjacency pair). The first part is a kind of an information request (with a slightly rise on IRA in order to ask for confirmation: does he work at IRA?) while the second part corresponds to the response of the same speaker in his own discourse ( $a h$ with a rise-fall pitch contour, of course no, it is the bad word! with a strong fall). However, after this turn, AP seems to use another voice that precisely participates in the first part of the utterance by adopting the point of view rejected immediately afterwards. AP animates this voice by increasing loudness, and emphasizing the utterance notably through the words "travaille"/"work" and "IRA". We also noted a hoarse voice associated or linked to the laughing heard in the voice. This shift is indeed heard by LJ who also laughs (in 321). LJ shows his prosodic orientation to the humorous tonality of AP by expressing a complement's turn in which prosodic cues exhibit the same pattern as AP.

Among the different prosodic orientation, Szcezpeck-Reed (2006) mentions the case in which interactants may display prosodic orientation by matching the previous speaker's prosodic design. There is also the case in which the interactants may complement a prior turn with a second structurally related prosodic design or they may continue previously unfinished prosodic patterns. The example examined here refers to a case of mapping prosody that consists of the activity of copying a previous speaker's prosodic pattern. The following turns from LJ and AP display the same prosodic pattern such as a strong lengthening of the last syllable or on the additional "euh", a very little modulation and slight falling pitch on the whole utterance, a similar duration of these successive utterances and laughter in their voices. If we look at the example (3), we can also describe it as a typical case of prosodic orientation where the reported speech completes the prior turn of LJ, -even if vocal cues are emphasized to create a prosodic chiming in-.

In the present example, the utterance in 404 shifts again to another person (himself) with a metacommunicative signal and a denial of the humorous nature of this previous sequence. Similarly LJ moves back to the serious mode in explaining once again the IRAA acronym (by overarticulating the different letters). In the next turn, AP moves again on the acronym (by emphasizing 'IRAA' in a "saoudite manner").

\section{- Petits Lu}

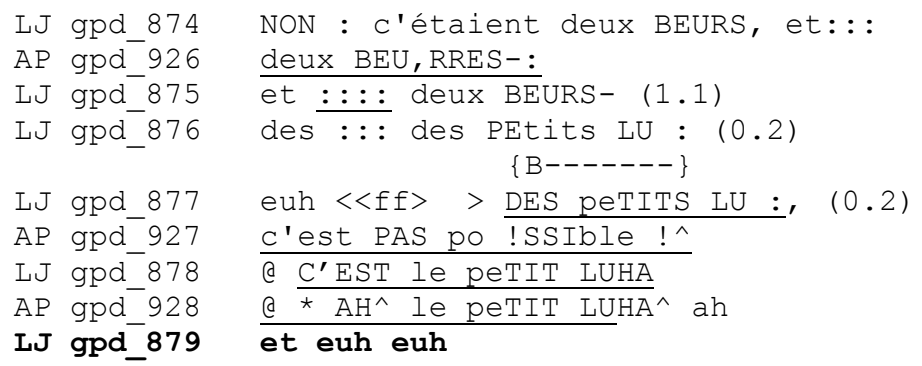

In this excerpt, LJ tells a story of a salesperson who came to sell door to door some cards. LJ explains that if he were alone, he would have sent him back but he did not dare to do it 
because he was with his girlfriend. This point is the moment when AP begins to produce his humorous utterances. He begins to tease LJ about his girlfriend asking about the color of her hair. This attempt to a humorous digression fails because LJ chooses to answer AP's question seriously about his girlfriend and goes on with his story. When LJ specifies that the sellers was also of Arabic descent, AP proceeds with this topics and begins to play with the double meaning of "beur" in French that means both Arab and butter. This time, LJ enters in the game and develops with AP a short humorous sequence where they play on this double meaning.

"Beur" is thus the polysemic connector which has two disjonctors. The first one is "beurre/butter" i.e. a phonic disjonctor and the second, more explicit is "des petits Lu"6 that presents the second unrealistic absurd and humorous meaning, i.e. the fact that two cookies are salespersons.

In this example, we show another case of co-construction by participants of a humorous sequence. The device used is exactly the same as in the previous example. The interlocutor (AP) comments again on the word produced by LJ by expressing a form of confirmation request (with a rise on BEU and a level pitch on "e" as a kind of suspension between the request and a proposition) overlapping with the turn of $\mathrm{LJ}$ on "et::::." . But here it is not AP but LJ who gives an answer in repeating once again "deux beurs" (with a flat configuration) but a very long pause ( $>1$ second) after he proposes his second script in a specific prosodic frame: lengthening on "des::::"des petits lus", with also a specific vocal quality (breathy on "pe" de petit and "lu"). AP follows with an increase of loudness, an overarticulation of each syllable ("c'est pas possible"!/ "it is not possible"!) and a rising-falling contour with a peak on the penultimate which sounds strange here (shift!). LJ repeats in overlap (877 "et" / "and" 927) his utterance in attempting to imitate a foreign accent (maghrebin yet). In 928, the laughter in the voice of AP can be heard and he also repeats the utterance by imitating the foreign accent. Finally, both interlocutors laugh and, once again, LJ and AP repeat the utterance with the same accent and the same prosodic delivery. This example illustrates a case of prosodic orientation with a prosodic matching in the last repetitions.

\section{- Rapport normaux / normal relationship}

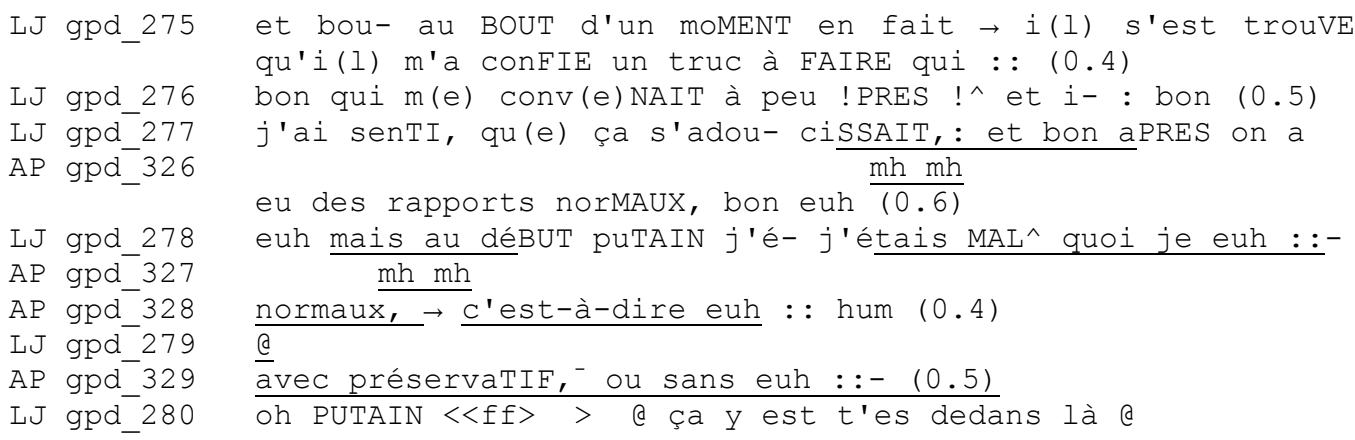

In the last excerpt, $\mathrm{LJ}$ is speaking about something that happened to him when he was doing an archaeological dig. He explains that at the beginning, he had a difficult relationship with another man and that, as the days passed, their relationship improved. The expression "normal relationship"/rapports normaux" is the connector from which LJ proceeds to modify and switch into a humorous mode of communication. Indeed, "normal relationship" may be interpreted with two different meanings. In other words, it potentially carries two different scripts: (i) the logical and expected script, i.e., a professional and/or friendly relationship with

\footnotetext{
${ }^{6}$ French brand of cookies.
} 
a colleague, (ii) a sexual script. AP proceeds to use the connector to render the second script unexpected and humorous (A 328, 329). If "condom" / "preservatif" is the explicit disjonctor that allows to reveal the second script AP's first attempt already produced when he repeated the term "normal". This attempt was successful as LJ's laughter shows. Even if LJ laughs, at the end, he produces a metacommunicative comment ("T'es dedans là" / "you're in") showing that if he had perceived humor he probably would not want to develop it too much.

AP produces backchannel signals in 326 and 327. Then, when he takes the floor in 328 on a similar level pitch, LJ can expect that it is a true confirmation request. But AP insists, pauses and complements his first pair part with the explicit disjonctor that carries the pitch contour described above (rise followed with high plateau) to characterize the confirmation request that functions as humorous. Even if the prosodic device is less glaring here, LJ can hear the humorous tonality (laughing). Moreover, it seems that the shift between lexical and prosodic cues precisely contributes to create humor. In this way, this last example differs from all the others observed in this paper. The non marked connector could be interpreted in the same way as the reported speech displaying no marked prosody. As Klewitz and Couper-Kuhlen explain (1999: 474) the absence of mark where it is expected is significant in the reported speech, and we claim that humor emerges in this specific context thanks to the absence of explicit prosodic marks.

\section{CONCLUSION}

In this paper, we focused on conversational humor in talk-in-interaction in order to understand how speakers co-construct and switch into a humorous mode of communication. Consequently, we wondered what exactly the role of prosodic cues was in conversational humor by analyzing them in their context, i.e., in their sequential environment. We could extract two discursive devices in which humor appears: reported speech and repetitions. In the former, we highlighted that the connector and the disjonctor could appear as simultaneously while they appear rather separately in the second device through successive repetitions that function as confirmation request and/or answer. Several studies have shown the role of prosodic cues in these devices independently of the humor phenomenon. Concerning the reported speech, we confirm here the importance of prosodic cues to animate different figures in speakers' discourse and more specifically to typify a character. This latter appears as the peak of humor sequence co-constructed gradually with several reported speeches from both interlocutors. Concerning the request/answer confirmation in the repetition's device, we highlight the role of the prosodic orientation (through different prosodic means) to show the successful co-construction of the humorous sequence. Finally, we demonstrate that not all the prosodic cues are specific to humor but participate in a congruence of cues that allow the creation of humor.

\section{REFERENCES}

Anderson, A., Bader, M., Bard, E., Boyle, E., Doherty, G., Garrod, S., Isard, S., Kowtko, J., Mc Allister, J., Miller, J., Sotillo, C., Thompson, H., Weinert, R. (1991) "The HCRC map task corpus", Language and Speech 34, 351-366.

Attardo S. (1994) Linguistic theories of humor, Berlin, New York, Mouton de Gruyter. Attardo S., Eisterhold J., Hay J. \& Poggi I (2003) "Multimodal markers of irony and sarcasm". Humor 16(2) 243-260

Bakhtin M. (1977) Le marxisme et la philosophie du langage, Paris, Ed. de Minuit, 233 p. ( $1^{\text {ère }}$ édition, 1929). 
Bariaud F. (1983) La genèse de l'humour chez l'enfant, Paris, PUF.

Bertrand R. (2008) <http://crdo.fr/voir_depot.php?langue=fr\&id=000027>

Bertrand R., Blache P., Espesser R., Ferré G., Meunier C., Priego-Valverde B., Rauzy S. (2008) "Le Cid - Corpus of Interactional Data - Annotation et Exploitation Multimodale de Parole Conversationnelle ", Traitement Automatique des Langues, vol. 49, n ${ }^{\circ}$ 3, 30 pages.

Bertrand R. \& Espesser R. (2002) "Voice diversity in conversation : a case study", in Bel B. \& Marlien I (éds), Speech Prosody 2002, Aix-en-Provence, 171-174.

Bertrand R. (2003) Etre soi avec les mots d'autrui, In J.-M. Merle (ed.) Le sujet, Paris: Ophrys, 269-280.

Bryant G. A. \& Fow Tree J.E. (2005) "Is there an ironic tone of voice?", Language and Speech, 48 (3), 257-277.

Couper-Kuhlen E. (1999) "Coherent voicing: On prosody in conversational reported speech", In Wolfram Bublitz \& Uta Lenk (eds.) Coherence in Spoken and Written Discourse: How to create it and how to describe it, Amsterdam: Benjamins, 11-32.

Couper-Kuhlen E. \& Selting M. (1996) Prosody in conversation, Cambridge University Press Couper-Kuhlen E \& Ford C. (2004) Sound Patterns in Interaction, John Benjamins Publishing Company.

Di Cristo A., Auran R., Bertrand R., Chanet C., Portes C. \& Régnier A. (2004) "Outils prosodiques et analyse du discours", CILL 30, n 1-3, 27-84.

Di Cristo A. (2000) "Vers une modélisation de l'accentuation du français", French Language Studies 10 (2), 27-44, Cambridge University Press.

Golopentja S. (1988) : «Interaction et histoire conversationnelles », in Cosnier, Gelas et Kerbrat-Orecchioni (eds), $1988: 69-81$.

Greimas, Algirdas Julien (1966) Sémantique structurale. Paris : PUF. Kerbrat-Orecchioni (eds), $1988: 69-81$.

Hirschberg J. (2002) "The pragmatics of Intonational meaning", in Bel B. \& Marlien I (éds), Speech Prosody 2002, Aix-en-Provence, 65-68.

Hutchby I and Wooffitt R. (1998) Conversation Analysis. Principles, Practices and Applications (Cambridge: Polity Press)

Klewitz G. \& Couper-Kuhlen E. (1999) "Quote-Unquote? The Role of Prosody in the Contextualization of Reported Speech Sequences", Pragmatics 9, 459-485.

Kotthoff H. (2006) "Oral genres of humor: On the dialectic of genre knowledge and creative authoring", Interaction and Linguistic Structures, No. 44.

Kristeva J. (1969) Sèmiotikè, Paris, Ed. du Seuil.

Laforest M. (1992) Le Back-Channel en situation d'entrevue, Québec, Université Laval, CIRAL.

Local J. (2007) "Phonetic detail in talk-in-interaction: on the deployment and interplay of sequential context and phonetic resources", Nouveaux cahiers de linguistique française 28 , 67-86, Université de Genève.

Morin V. (1966) "L’histoire drôle", Communications 8, 102-119.

Ogden R. (2004) "Non-modal voice quality and turn-taking in Finnish", in E. Couper-Kuhlen

\& C. Ford (eds), Sound Patterns in Interaction, John Benjamins Publishing Company, 29-62.

Perrin L., Deshaies D., Paradis C. (2003) Pragmatic functions of local diaphonic repetitions in conversation, Journal of Pragmatics 35, 1843-1860.

Priego-Valverde B. (2003) L'humour dans la conversation familière: description et analyse linguistiques, France, L'Harmattan.

Priego-Valverde B. (2007) : «Self-disparaging humor in conversation », in New Approaches to the Linguistics of Humor, Popa D \& Attardo S. (eds.): 15-34.

Raskin V. (1985) Semantic Mechanisms of Humor, D. Reidel Publishing Compagny, Dordrecht, Holland. 
Sacks H., Schegloff E.A. \& Jefferson G. (1974) "A simplest systematics for the organization of turn-taking for conversation", Language 50, 696-735.

Schegloff, Emanuel \& Sacks, Harvey (1973) "Opening Up Closings", Semiotica 8 (4), 289327.

Selting, M. (2000) "The construction of 'units' in conversational talk", Language in Society, 29: 477-517.

Szczepek Reed B. (2006) Prosodic orientation in English Conversation, Palgrave Macmillan. Vincent, Diane et Sylvie Dubois (1997) Le discours rapporté au quotidien, Québec, Nuit Blanche éditeur, collection Langue et pratiques discursives, $151 \mathrm{p}$.

Traverso V. (1996) La conversation familière. Analyse pragmatique des interactions, Lyon, Presses Universitaires de Lyon.

Vion R. (1992) La communication verbale. Analyse des Interactions, Paris, Hachette Supérieur.

Conventions of transcription (Selting 2004)

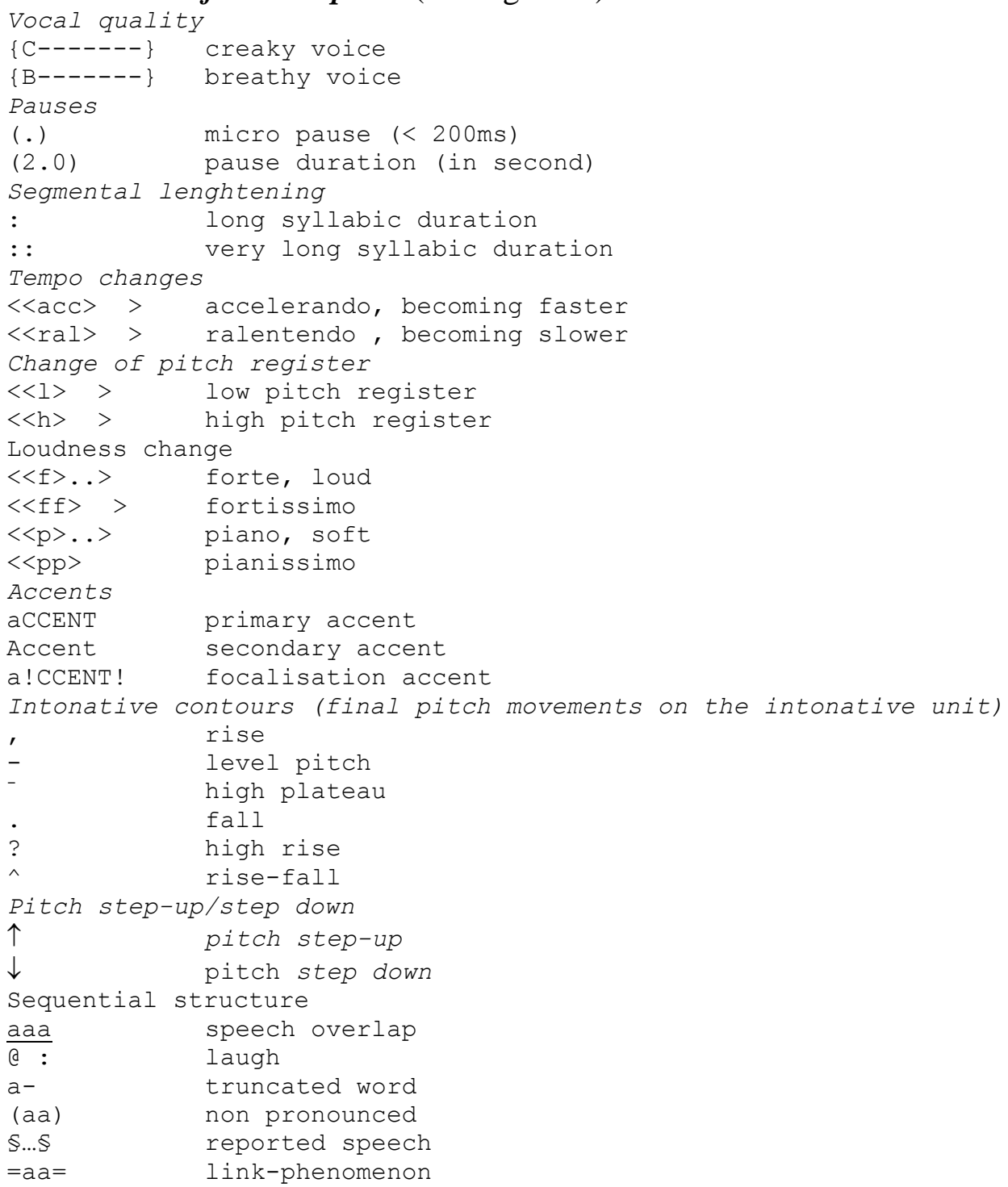

\section{ANNEXE}

(1)
AP gpd_253
not to say bullshits I think they di- they ti- they destroy the guy or they killed him I don't know
LJ gpd_178 there is really a thing uh @ 
AP gpd_254

AP gpd_255

LJ gpd_179

AP gpd_256

AP gpd_257

AP gpd_258

(2)

LJ gpd_180

LJ gpd_198

AP gpd_265a

AP gpd_265b

LJ gpd_199

AP gpd_265c

AP gpd_266

LJ gpd_200

AP gpd_267

LJ gpd_201

(3)

LJ gpd_306

LJ gpd_307

AP gpd_390

AP gpd_391

LJ gpd_308

AP gpd_392

AP gpd_393

AP gpd_393a

(4)

LJ gpd_412

AP gpd_490

AP gpd 490a

LJ gpd_413

AP gpd_490b

LJ gpd_414

AP gpd_490c

AP gpd_491

(...)

LJ gpd_429

LJ gpd_430

AP gpd_498a

AP gpd-499

AP gpd_499a

(5)

AP gpd 218

LJ gpd8140

AP gpd_219

LJ gpd_141

AP gpd_220

LJ gpd_142

(6)

LJ gpd_312

LJ gpd 313

LJ gpd_314

AP gpd_396

LJ gpd_315

AP gpd_397

LJ gpd_316

AP gpd 398

LJ gpd_317

LJ gpd_318

(7)

LJ gpd_320

LJ gpd_321

AP gpd_401

AP gpd_402 yeah it was hot well

@ maybe there is nothing to see uh

ah yeah well roxane will tell us

uh the guy uh

they told him you're a bad boy

but yeah well I don't remember it was hot and he told me that the uh they filtered totally everything

$\mathrm{mh} \mathrm{mh}$

they passed an encrypted movie of canal plus a porno movie

@

uh@ but wait it was the incident

@ that say

it's uh european terrorism

no it's it's it's don't laugh it was the diplomatic incident uh a kind of

goddammit you surprising me

the guys they took it very badly

already you well you say a thing well it's a fact period

like that he you re he begins looking at you uh you know as there was easiness a suspicion you say well it is

what

would you be vegetarian

kind of but what is this fucker uh and no I'm not a fucker but finally well it's

but hey you you participated to the gay pride

@ eh eh

eh eh

it it was a little curious and and a black dressed guy with black hairs a little like that $\mathrm{mh} \mathrm{mh}$

@

a bad look but you know like uh

@

I don't know the gravedigger in Lucky Luke or a thing like that but with some

@ yeah uh

the rapist of the wood

there they propose me to go uh with them in prospecting in I don't remember where uh

to the esterel or I don't know uh during uh the m @ during the month of august you know I told myself but wait uh thy will kill me

@

come to prospect with us little boy eh eh

@

they were in the powder

at the bottom there were the eggs uh @

oh my god lyophilize you know hop pfft

yeah

immediately it begin to pump up you had a cockroach like that

it's it's milk cocoa well if I see some sequins here some white sequins no no there are eggs

then like uh $\mathrm{h}$ his his son hey well it's

his son it's him you saw at uh

for the new year eve at Marianne's place the tall

who is the brown

the tall brown yeah

ah yeah yeah yeah the tall brown with a white shoe

and and two two black shoes

two black shoes

yeah@

all black and two black shoes

and his father its him who mana who is architect uh who work at

at I.R.A.A. uh the researche institute of architecture on

at I.R.A. pff

he works at I.R.A. 
LJ gpd_321a

LJ gpd_322

AP gpd_403

LJ gpd_323

AP gpd 404

LJ gpd 323a

AP gpd_405

AP gpd_405a

(8)

LJ gpd 874

LJ gpd_875

AP gpd_926

LJ gpd_876

LJ gpd_877

AP gpd_927

LJ gpd_878

AP gpd 928

LJ gpd 879

(9)

LJ gpd_275

LJ gpd_276

LJ gpd 277

AP gpd_326

LJ gpd_278

AP gpd_327

AP gpd_328

LJ gpd_279

AP gpd_329

LJ gpd_280 and he blows up uh

ah@ and he put the detonators uh

yeah he is watchmaker at I.R.A. @

ah that's not funny

no it's I.R.A.A. uh archit uh research institute on antique architecture

I.R.A.

goddammit

no it was two Arabs and and

and two Arabs

two Arabs uh

some Petits Lu

uh some Petits Lu

it's not possible

(a) it's the Petit Lu

@ ah the Petit Lu

and uh uh

and af after a moment in fact he confided me a thing to do that

well what conveys me a little and well

I felt that softened and well after we had normal relationship well uh hm hm

uh but at the beginning goddammit I felt bad I uh

hm hm

normal meanings uh

@

with condom or without uh

oh goddammit you're in here @ 